\title{
PENGEMBANGAN MODEL BISNIS HALAL LOGISTIK TRANSPORTASI BERBASISKAN BUSINESS MODEL CANVAS (BMC)
}

\author{
Made Irma Dwiputranti \\ Prodi D3 Logistik Bisnis, Politeknik Pos Indonesia \\ email : madeirma@poltekpos.ac.id
}

\begin{abstract}
ABSTRAK
Konsep dasar dari logistik umum dan logistik halal sebenarnya sama, yang membedakan adalah pada logistik halal dilakukan dengan memastikan proses-proses dalam supply chain melakukan pemisahan muatan halal dari kargo non-halal. Hal ini perlu dilakukan untuk menghindari kontaminasi silang dan memastikan bahwa sepanjang sistem logistik produk tersebut terjamin halal, Oleh karena itu logistik halal dapat dinyatakan sebagai penerapan konsep halal sepanjang aktivitas supply chain dari supplier, manufaktur, pergudangan, transportasi dan pendistribusian produk guna memastikan status halal suatu produk. Apabila hal tersebut dilakukan akan menghasilkan output logistik halal yang sesuai standar keinginan customer.

Penelitian akan dilakukan melalui wawancara dan survei, hasilnya akan dipergunakan untuk mengidentifikasi proses bisnis dan mengetahui aktivitas bisnis apa saja yang dilakukan dan siapa saja pelaku bisnis yang terlibat, dari proses bisnis tersebut kemudian dibuatlah suatu model bisnis untuk mengembangkan logistik biasa ke halal logistik dengan berbasiskan Business Model Canvas (BMC). Business Model Canvas (BMC) terdiri dari 9 elemen, yaitu customer segments, value propositions, channels, customer relationship, revenue streams, key resources, key activities, key partnership and cost structure.

Hasil dari penelitian ini adalah diperolehnya model halal logistik berbasiskan kanvas model yang dapat diterapkan di PT Iron Bird, yang terbagi menjadi 4 kategori yaitu: 1)Customer yang memiliki potensi dalam halal logistik adalah industri yang bergerak dalam bidang fast moving, consumer goods, retail, raw material and pharmacy 2) Penawaran (value propositions) yaitu penawaran kepada customer mengenai pengiriman yang menjamin produk halal, pendistribusian untuk pengembalian barang atau return, segregasi untuk Less than Truck Load (LTL), packaging ulang untuk barang yang terkontaminasi, label dan dokumen halal, pembersihan unit yang sesuai standar, kelengkapan safety, transparancy and trust, on time delivery, dan cost yang sesuai dengan pelayanan yang diberikan 3)Resources dengan mengelola sumber daya utama melalui tim khusus untuk menangani barang yang terkontaminasi, ketersediaan kendaraan, layanan yang diberikan, pengemasan untuk barang yang terkontaminasi dan label serta dokumen halal 4) Financial melalui pelayanan yang diberikan . Key Performance Indicators (KPI) yang sesuai dengan standar halal logistik yang terdiri dari: Quality, Time, Cost dan Risk.
\end{abstract}

Kata Kunci: halal logistik, transportasi, model bisnis, value creation, key performance indicators

\section{ABSTRACT}

The basic concept of general logistics and halal logistics are actually the same, the difference is that halal logistics is carried out by ensuring that processes in the supply chain separate halal cargo from non-halal cargo. This needs to be done to avoid cross-contamination and ensure that as long as the logistics system of the product is guaranteed halal, therefore halal logistics can be expressed as the application of the halal concept throughout the supply chain activities of suppliers, manufacturing, warehousing, transportation and product distribution to ensure the halal status of a product. If this is done, it will produce halal logistic output according to the standards of the customer's wishes.

The research will be carried out through interviews and surveys, the results will be used to identify business processes and find out what business activities are carried out and who are the business actors involved, from the business process a business model is then created to develop ordinary logistics to halal logistics based on a Business Model Canvas (BMC). The Business Model Canvas 
(BMC) consists of 9 elements, namely customer segments, value propositions, channels, customer relationships, revenue streams, key resources, key activities, key partnerships and cost structures. The result of this research is to obtain a canvas-based halal logistics model that can be applied at PT Iron Bird, which is divided into 4 categories, namely: 1) Customers who have potential in halal logistics are industries engaged in fast moving, consumer goods, retail., raw material and pharmacy 2) Value propositions, namely offers to customers regarding delivery that guarantees halal products, distribution to return goods or return, segregation for Less than Truck Load (LTL), re-packaging for contaminated goods, labels and documents halal, cleaning units according to standards, completeness of safety, transparency and trust, on time delivery, and costs in accordance with the services provided 3) Resources by managing main resources through a special team to handle contaminated goods, availability of vehicles, services provided, packaging for contaminated goods and labels and documents halal 4) Financial through the services provided. Key Performance Indicators (KPI) in accordance with halal logistics standards which consist of: Quality, Time, Cost and Risk.

Keywords: halal logistics, transportation, business models, value creation, key performance indicators

\section{PENDAHULUAN}

Konsep halal tidak hanya terbatas pada produk itu sendiri tetapi juga meliputi proses, distribusi, penanganan, pengemasan dan penyimpanan produksi [i]. Oleh karena itu, konsep halal tersebut harus diterapkan di setiap aktivitas supply chain, dari mulai supplier sampai produk tersebut dikonsumsi pelanggan menyatakan bahwa dalam proses penanganannya produk halal harus dipisahkan dan tidak dapat dicampur dengan produk haram [ii]. Hal ini menyebabkan konsep halal logistik harus dikembangkan dan dipahami oleh semua industri bukan hanya industri makanan halal.

Logistik halal merupakan kegiatan fisik penyimpanan dan pengiriman barang yang dilengkapi dengan informasi dan komunikasi terarah antara pihak yang terkait di sepanjang alur supply chain dengan menerapkan konsep halal didalamnya [iii].

Konsep dasar dari logistik umum dan logistik halal sebenarnya sama, yang membedakan adalah pada logistik halal dilakukan dengan memastikan proses-proses dalam supply chain melakukan pemisahan muatan halal dari kargo non-halal. Dalam hal ini juga meliputi proses logistik atau tracking. Ada tiga prinsip yang mendasari pembentukan logistik halal, yaitu: Terhindarnya kontaminasi, Terhindarnya dari kesalahan, dan Adanya jaminan bahwa operasional logistik konsisten terhadap konsep halal [iv]. Hal ini perlu dilakukan untuk menghindari kontaminasi silang dan memastikan bahwa sepanjang sistem logistik produk tersebut terjamin halal. Oleh karena itu, logistik halal dapat dinyatakan sebagai penerapan konsep halal sepanjang aktivitas supply chain dari supplier, manufaktur, pergudangan, transportasi dan pendistribusian produk guna memastikan status halal suatu produk. Apabila hal tersebut dilakukan akan menghasilkan output logistik halal yang sesuai standar keinginan customer.

Bagi perluasan bisnis hal ini adalah salah satu hal yang dapat dijadikan potensi bagi perusahaan untuk memberikan nilai yang unggul bagi konsumen, yaitu perusahaan dapat memastikan dan memberikan jaminan halal terhadap keseluruhan proses supply chain. Jaminan halal supply chain ini tentunya akan menjadi bisnis yang menggiurkan bagi para industri apabila dapat dimanfaatkan dengan baik, mengingat masyarakat Indonesia yang mayoritasnya muslim dan kesadaran masyarakat muslim terhadap kehalalan makin berkembang, sebagai negara dengan penduduk muslim terbesar di dunia, halal menjadi isu dan tuntutan sebagian besar konsumen di Indonesia.

Permasalahan yang dihadapi oleh PT Iron Bird adalah penerapan halal logistik belum sepenuhnya dilakukan walaupun telah memiliki sertifikat halal logistik. Kenyataan ini dapat dilihat dari layanan yang diberikan belum sesuai keinginan konsumen yang menginginkan pelayanan jasa transportasi sesuai dengan standar halal dan baru hanya melaksanakan di sebagian proses operasional saja. Hal ini terjadi karena PT Iron Bird belum memiliki model bisnis dan Key Performance Indicators, sehingga belum maksimal dan belum teridentifikasi dengan jelas dalam melaksanakan proses bisnisnya untuk memenuhi keinginan customer. Key Performance Indicator (KPI) biasanya digunakan untuk menilai kondisi suatu bisnis serta tindakan apa yang diperlukan untuk menyikapi kondisi tersebut. Sistem pengukuran yang efektif harus dibangun untuk mencapai tiga tujuan yaitu pemantauan, pengendalian dan mengarahkan operasi logistik [v]. 
Pada saat ini Marketing PT Iron Bird khususnya yang memiliki interaksi langsung dengan customer belum memahami secara jelas mengenai layanan transportasi halal logistik, sedangkan permasalahan untuk customer yang sudah bekerjasama dengan PT Iron Bird yaitu belum teridentifikasinya value propositions customer. Value proposition merupakan manfaat atau benefit yang didapatkan oleh customer jika bergabung dengan perusahaan, hal ini sesuai dengan penelitian yang telah dilakukan sebelumnya terhadap Perencanaan model bisnis usaha food and beverage edamame goreng, dimana komponen value proposition sangatlah berpengaruh terhadap model bisnis perusahaan mereka [vi]. Pada saat ini terdapat banyak kendala yang dihadapi oleh perusahaan-perusahaan di Indonesia dalam menerapkan konsep halal ini adalah kurangnya pemahaman bagaimana konsep halal diterapkan sesuai dengan peranan masing-masing perusahaan dalam supply chain, dan kurangnya kerjasama dengan pihak lain dalam pengembangan supply chain logistik halal. Oleh karena itu, perlu dikembangkan model bisnis untuk berbagai industri di Indonesia khususnya yang bergerak di bidang transportasi dengan menerapkan konsep halal didalamnya. Dimana ketika menangani logistik dan supply chain produk halal, model bisnis industri tersebut berbeda dan lebih kompleks daripada model bisnis pada umumnya. Pengembangan model bisnis halal tersebut dapat dilakukan dengan menggunakan metode Business Model Canvas (BMC).

\section{LANDASAN TEORI}

Business Model Canvas (BMC) merupakan sebuah alat bantu untuk mendeskripsikan, menganalisis, dan merancang model bisnis. Business Model Canvas (BMC) berisi 9 elemen yang dapat dikembangkan untuk membuat proses bisnis. Proses bisnis dalam penelitian ini terkait dengan aktivitas dan pelaku bisnis. Business Model Canvas (BMC) terdiri dari 9 elemen, yaitu sebagai berikut [vii]:

1. Customer Segments atau Segmen Pelanggan

Blok bangunan segmen pelanggan menggambarkan sekelompok orang atau organisasi berbeda yang ingin dijangkau atau dilayani oleh perusahaan. Pelanggan adalah inti dari semua model bisnis. Tanpa pelanggan (yang dapat memberikan keuntungan) tidak ada perusahaan yang mampu bertahan dalam waktu lama. Untuk lebih memuaskan pelanggan, perusahaan dapat mengelompokkan mereka dalam segmen-segmen berbeda berdasarkan kesamaan kebutuhan, perilaku, atau atribut lain. Sebuah model bisnis dapat menggambarkan satu atau beberapa segmen pelanggan, besar ataupun kecil.

2. Value Propositions atau Prorposisi Nilai

Blok bangunan proposisi nilai menggambarkan gabungan antara produk dan layanan yang menciptakan nilai untuk segmen pelanggan spesifik. Proposisi nilai menciptakan nilai untuk segmen pelanggan melalui paduan elemen-elemen berbeda yang melayani kebutuhan segmen tersebut. Nilai dapat bersifat kuantitatif misalnya harga dan kecepatan layanan atau kualitatif misalnya desain dan pengalaman pelanggan. Proposisi nilai adalah alasan yang membuat pelanggan beralih dari satu perusahaan ke perusahaan lain. Proposisi nilai dapat memecahkan masalah pelanggan atau memuaskan kebutuhan pelanggan. Setiap proposisi nilai berisi gabungan produk dan/atau jasa tertentu yang melayani kebutuhan segmen pelanggan spesifik. Dalam hal ini, proposisi nilai merupakan kesatuan atau gabungan manfaat-manfaat yang ditawarkan perusahaan kepada pelanggan.

3. Channels atau Saluran

Blok bangunan saluran menggambarkan bagaimana sebuah perusahaan berkomunikasi dengan segmen pelanggannya dan menjangkau mereka untuk memberikan proposisi nilai. Saluran komunikasi, distribusi, dan penjualan merupakan penghubung antara perusahaan dan pelanggan. Saluran adalah titik sentuh pelanggan yang sangat berperan dalam setiap kejadian yang mereka alami.

4. Customer Relationship atau Hubungan Pelanggan

Blok bangunan hubungan pelanggan_menggambarkan berbagai jenis hubungan yang dibangun perusahaan bersama segmen pelanggan yang spesifik. Sebuah perusahaan harus menjelaskan jenis hubungan yang ingin dibangunnya bersama segmen pelanggan. Hubungan dapat bervariasi mulai dari yang bersifat pribadi sampai otomatis. Hubungan pelanggan dapat didorong oleh motivasi berikut: 
- Akuisisi pelanggan.

- Mempertahankan pelanggan.

- Peningkatan penjualan (upselling).

5. Revenue Streams atau Arus Pendapatan

Blok bangunan arus pendapatan menggambarkan uang tunai yang dihasilkan perusahaan dari masing-masing segmen pelanggan (biaya harus mengurangi pendapatan untuk menghasilkan pemasukan). Jika pelanggan adalah inti dari model bisnis, maka arus pendapatan adalah urat nadinya.

6. Key Resources atau Sumber Daya Utama

Blok bangunan sumber daya utama menggambarkan aset-aset terpenting yang diperlukan agar sebuah model bisnis dapat berfungsi. Setiap model bisnis memerlukan sumber daya utama. Sumber daya ini memungkinkan perusahaan menciptakan dan menawarkan proposisi nilai, menjangkau pasar, mempertahankan hubungan dengan segmen pelanggan dan memperoleh pendapatan. Kebutuhan sumber daya utama berbeda-beda sesuai jenis model bisnis.

7. Key Activities atau Aktivitas Kunci

Blok bangunan aktivitas kunci menggambarkan hal-hal terpenting yang harus dilakukan perusahaan agar model bisnisnya dapat bekerja. Setiap model bisnis membutuhkan sejumlah aktivitas kunci, yaitu tindakan-tindakan terpenting yang harus diambil perusahaan agar dapat beroperasi dengan sukses. Seperti halnya sumber daya utama, aktivitas-aktivitas kunci juga diperlukan untuk menciptakan dan memberikan proposisi nilai, menjangkau pasar, mempertahankan hubungan pelanggan, dan memperoleh pendapatan. Seperti sumber daya utama, aktivitas-aktivitas kunci berbeda bergantung pada jenis model bisnisnya.

8. Key Partnership atau Kemitraan Utama

Blok bangunan kemitraan utama menggambarkan jaringan pemasok dan mitra yang membuat model bisnis.

9. Cost Structure atau Struktur Biaya

Struktur biaya menggambarkan semua biaya yang dikeluarkan untuk mengoperasikan model bisnis. Blok bekerja. Perusahaan membentuk kemitraan dengan berbagai alasan dan kemitraan menjadi landasan dari berbagai model bisnis. Perusahaan menciptakan aliansi untuk mengoptimalkan model bisnis, mengurangi resiko atau memperoleh sumber daya mereka. Bangunan ini menjelaskan biaya terpenting yang muncul ketika mengoperasikan model bisnis tertentu. Menciptakan dan memberikan nilai, mempertahankan hubungan pelanggan dan menghasilkan pendapatan menyebabkan timbulnya biaya.

\section{METODE PENELITIAN}

\section{Alat dan Bahan}

Alat yang digunakan untuk penelitian yaitu wawancara dan survey

Pengumpulan data melalui pengamatan langsung ke lapangan agar lebih mengetahui kondisi sebenarnya yang terjadi dilapangan, sehingga dapat memperoleh data secara akurat. Dalam pengamatan ke lapangan terjadi proses wawancara dengan customer PT Iron Bird yaitu PT Ivomas Salim Pratama dan 7-Eleven. Wawancara yang dilakukan berkaitan dengan proses penerapan halal logistik dan distribusi.

\section{Metode Penelitian}

Pada tahapan perencanaan bisnis model kanvas, beberapa hal yang harus dilakukan adalah menentukan komponen dalam model bisnis kanvas untuk PT Iron Bird. Komponen-komponen bisnis dalam model bisnis awal ini kemudian diuji kesesuaiannya sehingga diperoleh perubahan-perubahan untuk perbaikan komponen-komponen model bisnis kanvas berdasarkan masukan-masukan yang ada. Tahapan dalam perancangan komponen- komponen dalam model bisnis kanvas. 


\section{Validasi}

Hasil wawancara antara penulis dengan PT Ivomas Salim Pratama dan 7-Eleven terlebih dahulu dibuat rekapitulasi oleh penulis. Setelah itu, penulis melakukan validasi ke PT Ivomas Salim Pratama dan 7-Eleven untuk mengetahui kebenaran hasil wawancara tersebut.

\section{Metode Pengolahan Data}

Pada penelitian ini metode yang dilakukan adalah metode deskriptif dengan pendekatan studi kasus. Metode penelitian deskriptif digunakan untuk memperoleh gambaran informasi, penjelasan, dan kondisi yang berkait dengan obyek penelitian secara faktual akurat dan sistematis. Metode yang dilakukan adalah dengan menggunakan pendekatan business model canvas melalui wawancara dan survey yang dilakukan terhadap customer PT Iron Bird yaitu 7-Eleven dan PT Ivomas Salim Pratama. Model bisnis kanvas terdiri dari sembilan komponen bisnis yang dapat dilihat pada Gambar 1.

Model bisnis kanvas memiliki komponen bisnis. Kesembilan komponen bisnis yang ada pada model bisnis kanvas adalah sebagai berikut (urut dari kanan ke kiri):

1. Customer segment (CS), yaitu menentukan segmen target customer dari produksi edamame goreng yang akan dikembangkan,

2. Value proposition (VP), yaitu memperkirakan kebutuhan customer.

3. Customer relationship (CR), yaitu mendefinisikan hubungan antara sektor usaha dengan customer,

4. Channel $(\mathrm{CH})$, yaitu suatu cara untuk mencapai customer,

5. Revenue stream (RS) yaitu representasi dari jalur penerimaan uang yang akan diterima dari setiap customer segment,

6. Key resource (KR) adalah sumber daya utama yang menjelaskan mengenai asset terpenting yang diperlukan dalam membuat model bisnis,

7. Key activities (KA) adalah kegiatan utama,

8. Key partners (KP) adalah kunci kemitraan yang menjelaskan jaringan pemasok dan mitra,

9. Cost structure (CR) adalah struktur biaya yang menggambarkan semua biaya dikeluarkan.

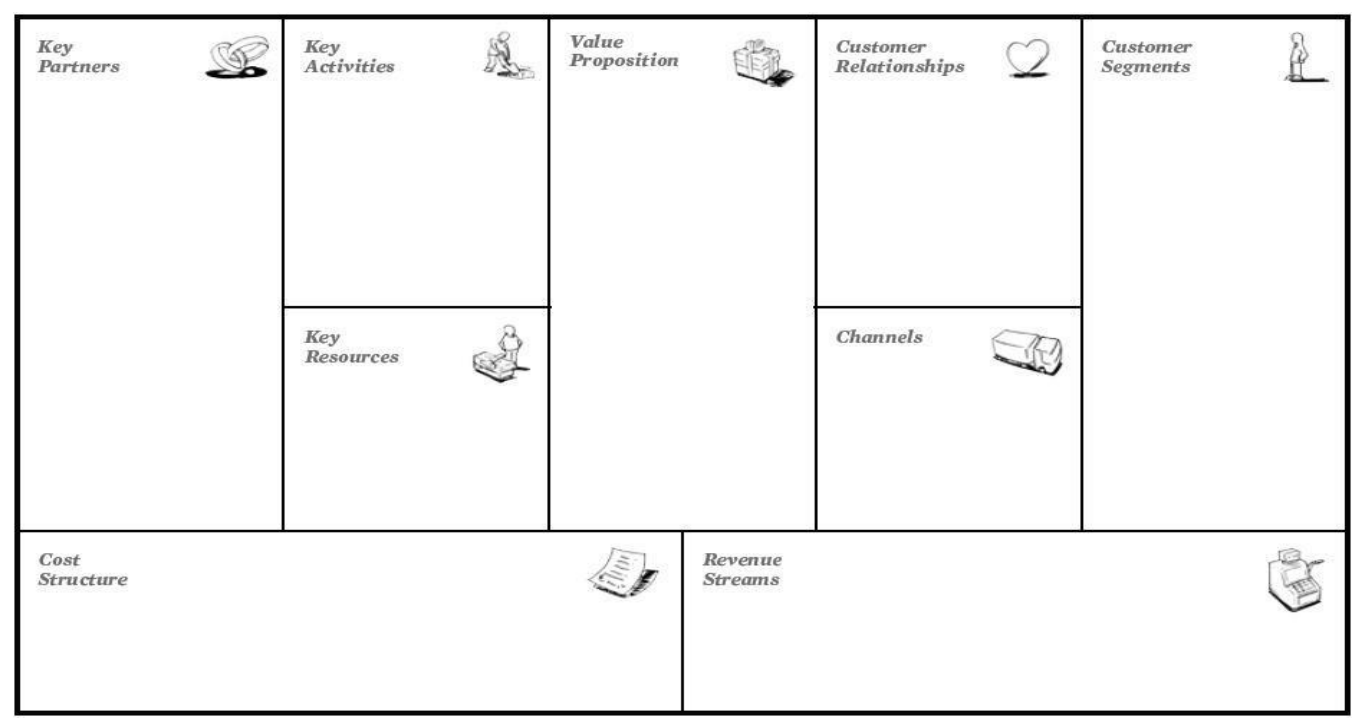

Gambar 1. Komponen bisnis pada model bisnis kanvas (Osterwalder et al., 2015). 


\section{HASIL DAN PEMBAHASAN}

Model pemecahan masalah yang digunakan yakni berbasiskan Business Model Canvas (BMC). Business Model Canvas (BMC) merupakan sebuah model bisnis yang mendeskripsikan cara sebuah perusahaan atau organisasi untuk menciptakan, memberikan dan mendapatkan nilai bagi perusahaan maupun customer dibawah ini adalah hasil rancangan model bisnis setelah melalui survei, wawancara dan penyebaran kuesioner yang diharapkan tepat dan sesuai untuk PT Iron Bird, sehingga dapat diaplikasikan dalam penerapan halal logistik transportasi agar PT Iron Bird dapat mengetahui nilai seperti apa yang diharapkan oleh customer. Berikut adalah model bisnis kanvas PT Iron Bird.

\begin{tabular}{|c|c|c|c|c|}
\hline Key Partners & Key Activities & Value Propositions & Customer Relationship & Customer Segments \\
\hline $\begin{array}{l}\text { 1. Majelis Ulama } \\
\text { Indonesia (MUI). } \\
\text { 2. Perbankan dan } \\
\text { asuransi syariah*. } \\
\text { 3. Asosiasi } \\
\text { Perusahaan Truk } \\
\text { Indonesia } \\
\text { (APTRINDO). }\end{array}$ & $\begin{array}{l}\text { Key Resources } \\
\text { 1. Tim khusus untuk menangani barang } \\
\text { yang terkontaminasi.* } \\
\text { 2. Kendaraan. } \\
\text { 3. Layanan Less than Truck Load (LTL) } \\
\text { dan Full than Truck Load (FTL). } \\
\text { 4. Pengem asan untuk barang } \\
\text { terkontaminasi.* } \\
\text { 5. Label dan dokumen halal.* }\end{array}$ & 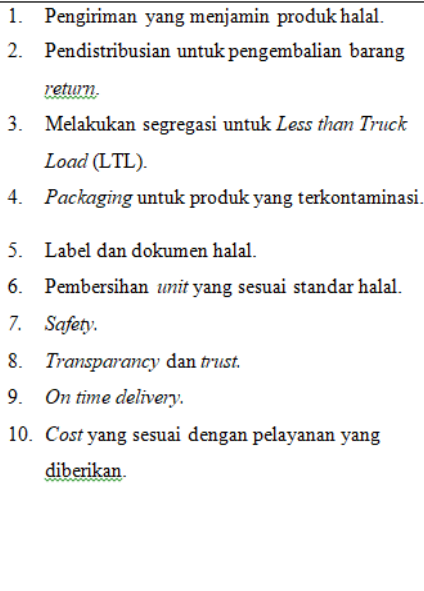 & $\begin{array}{l}\text { 1. Bantuan operasional. } \\
\text { 2. Bantuan operasional } \\
\text { yang khusus. }\end{array}$ & \begin{tabular}{|ll} 
1. & Industri Fast \\
& Moving Consumer \\
& Goods (FMCG). \\
2. & Retail \\
3. & Pharmacy. \\
4. & Raw Material
\end{tabular} \\
\hline $\begin{array}{l}\text { Cost Structure } \\
\begin{array}{ll}\text { 1. } & \text { Fix cost } \\
\text { 2. } & \text { Variabel cost }\end{array}\end{array}$ & \multicolumn{4}{|c|}{$\begin{array}{l}\text { Revemue Streams } \\
\text { 1. Biaya penggunaan } \\
==\text { Revemue }\end{array}$} \\
\hline
\end{tabular}

Gambar 2. Model Bisnis Kanvas PT.Iron Bird

Penjelasan Business Model CanvasS (BMC) Key Partners atau mitra utama yang dimiliki PT Iron Bird ada 3 yaitu:

- Majelis Ulama Indonesia (MUI).

Sebagai mitra yang membantu PT Iron Bird dalam melakukan penerapan sistem jaminan halal logistik dengan dikeluarkannya setifikat Halal Assurance System Status.

- Perbankan dan Asuransi Syariah.

Sebagai mitra yang berperan dalam melakukan transaksi keuangan yang berbasis syariah, karena sistem keuangan syariah dapat mendukung logistik yang halal.

- Asosiasi Pengusaha Truk Indonesia (APTRINDO).

Sebagai mitra yang berperan dalam aliansi transportasi. Asosiasi ini diperlukan apabila PT Iron Bird mengalami kekurangan unit kendaraan, maka dapat dibantu oleh anggota Aptrindo.

1. Key Activities atau aktivitas kunci yang dimiliki PT Iron Bird ada 6, yaitu:

- Distribusi/Pengiriman Barang.

PT Iron Bird sebagai perusahaan jasa transportasi memiliki kegiatan distribusi yang melayani ekspor, impor, domestik dan kargo.

- Cleaning Unit.

Pembersihan unit yang dilakukan oleh PT Iron Bird melalui perawatan harian dan mingguan masih belum cukup untuk customer. Customer menginginkan pembersihan unit dilakukan pada saat sebelum dan setelah pemakaian. 
- Segregasi.

Untuk pengiriman barang yang menggunakan Less than Truck Load (LTL) harus dilakukan segregasi, agar barang tidak terkontaminasi apabila dalam pengiriman tersebut ada produk non halal.

- Labeling dan Dokumen.

Pemberian label halal dari PT Iron Bird sangat berguna untuk mempermudah proses distribusi, apalagi jika distribusi dilakukan dengan Less than Truck Load (LTL). Labeling halal logistik dapat diberikan pada tiap palet atau tiap kardus barang sebagai penanda antara barang yang dikirimkan dengan pengiriman halal logistik dan pengiriman logistik biasa.

- Packaging.

Selama proses distribusi berlangsung, packaging ulang sangat dibutuhkan apabila terjadi kontaminasi, karena jika terjadi kontaminasi dalam perjalanan distribusi PT Iron Bird harus mengambil tindakan dengan melakukan packaging ulang agar barang yang terkontaminasi tidak menyebar ke barang lain. Barang yang di packaging ulang dapat dilakukan reverse logistik, sesuai dengan keinginan customer selaku pemilik barang.

- Pengembalian Barang (Return).

Tidak hanya sebagai penyedia jasa transportasi untuk melayani kegiatan ekspor, impor, domestik dan kargo PT Iron Bird juga bisa melayani kegiatan distribusi untuk pengembalian barang (return) yang sudah expired, work out, cacat dan rusak.

3.Key Resources atau sumber daya utama yang dimiliki PT Iron Bird ada 5, yaitu:

- Tim Khusus untuk Menangani Barang yang Terkontaminasi.

Tim ini merupakan tim khusus yang harus merespon dengan cepat jika terjadi kontaminasi pada barang saat pengiriman.

- Jumlah Unit Kendaraan.

Unit di PT Iron Bird ada dua jenis yaitu trailer dan box. Untuk jumlah trailer

ada 181 unit dan jumlah box ada 167 unit.

- Jenis layanan PT Iron Bird memiliki dua layanan yaitu:

a. Less than Truck Load (LTL) yang merupakan muatan dalam satu unit yang berisi beberapa barang milik beberapa pengirim yang digabungkan dalam satu unit. Layanan ini digunakan untuk muatan dengan kapasitas 30kg-2000kg yang dapat melayani kiriman ke Semarang dan Surabaya.

b. Full than Truck Load (FTL) yang merupakan muatan dalam satu unit yang hanya berisi barang milik satu pengirim. Layanan ini bisa digunakan untuk muatan dengan kapasitas berapapun yang dapat melayani kiriman ke Sumatra sampai batas Palembang, Jawa dan Bali.

- Pengemasan untuk Barang yang Terkontaminasi.

Selama proses distribusi menggunakan Less than Truck Load (LTL) terdapat kemungkinan terjadi kontaminasi dalam perjalanan, sehingga PT Iron Bird harus melakukan pengemasan ulang dengan kemasan yang telah disediakan. Hal ini perlu dilakukan agar barang yang terkontaminasi tidak menyebar ke barang lain.

- Label dan Dokumen Halal

Pemberian label halal dan dokumen yang menyatakan bahwa proses pengiriman dilakukan dengan prosedur halal logistik PT Iron Bird. Hal ini akan membuat konsumen merasa aman terhadap perlakuan barang kirimannya dan menjamin bahwa proses pengiriman sesuai standar halal logistik. Label barang terkontaminasi perlu diberi identifikasi dengan label khusus agar pihak receiving atau pihak yang terlibat dalam proses bongkar muat mengetahui bahwa barang tersebut rusak atau 
terkontaminasi.

2. Value Propositions atau proposisi nilai yang dimiliki oleh PT Iron Bird ada 10, yaitu:

- Pengiriman yang Menjamin Produk Halal.

Adanya sertifikat Halal Assurance System Status merupakan sebuah nilai lebih yang bisa ditawarkan PT Iron Bird ke customer. Sertifikat tersebut telah menunjukkan bahwa PT Iron Bird memberikan jaminan halal terhadap produk yang akan di distribusikan.

- Pengembalian Barang (Return).

Selain menjalankan kegiatan ekspor, impor, domestik dan kargo PT Iron Bird bisa menambahkan kegiatan untuk melayani pengiriman barang (return) yang biasanya dikarenakan expired, work out, rusak dan cacat.

- Melakukan Segregasi untuk Less than Truck Load (LTL)

Distribusi barang untuk yang menggunakan Less than Truck Load (LTL) harus dilakukan segregasi guna menghindari terjadinya kontaminasi, karena dalam satu unit terdiri dari banyak barang.

- Packaging untuk Produk yang Terkontaminasi

Menyediakan packaging ulang apabila terjadi kontaminasi dalam perjalanan distribusi. Hal ini bertujuan agar barang yang terkontaminasi tidak menyebar ke barang lain. Barang yang terkontaminasi tidak boleh dibuang di jalan dan tetap harus dikirim sampai ke tujuan. Jika sudah sampai dibagian receiving milik customer, barang yang terkontaminasi dapat dilakukan proses reverse logistik sesuai dengan jenis barang dan keinginan customer.

- Label dan Dokumen Halal

Harus ada label dan dokumen yang menyatakan bahwa proses distribusi yang dilakukan PT Iron Bird sesuai dengan halal logistik. Label terkontaminasi sebagai identifikasi tambahan untuk memudahkan proses penerimaan barang.

- Pembersihan Unit yang Sesuai Standar

PT Iron Bird melakukan pembersihan pada saat sebelum dan setelah pemakaian unit. Hal ini bertujuan agar kebersihan unit lebih terjamin. Pembersihan tambahan di PT Iron Bird dilakukan setiap minggunya.

- Safety

Adanya safety yang disediakan oleh PT Iron Bird untuk driver, seperti seragam, kartu identitas, dan sepatu safety dan kelengkapan alat unit seperti kotak obat, pengganjal ban dan alat pemadam api. Selain itu, juga harus ada pemberian pelatihan dan pengarahan kepada driver mengenai keselamatan dalam berkendara.

- Transparancy and Trust

Dalam proses bongkar muat PT Iron Bird harus bisa meyakinkan customer jika proses dilakukan secara transparan. Artinya PT Iron memiliki keterbukaan terkait proses pengiriman barang dan PT Iron Bird tidak membedakan customer yang satu dengan yang lain. Semua customer mendapatkan layanan dan perlakuan yang sama. Melalui transparancy dan trust dapat dilakukan proses evaluasi oleh PT Iron Bird.

- On Time Delivery

Pendistribusian barang harus dilakukan oleh PT Iron Bird harus dilakukan secara on time sesuai dengan estimasi waktu yang telah dibuat oleh PT Iron Bird, misalnya ke Surabaya 48 jam dan ke Semarang 36 jam. Hal ini harus benar-benar dilakukan, karena apabila terjadi keterlambatan pengiriman akan mengakibatkan pada ketidakpercayaan customer untuk menggunakan jasa PT Iron Bird. Keterlambatan juga berdampak pada semua proses, sehingga menjadi tertunda dan lama. 
- Cost yang Sesuai dengan Pelayanan yang Diberikan

Customer akan sanggup membayar lebih apabila mendapatkan pelayanan yang sesuai. Hal inilah yang harus dibangun oleh PT Iron Bird jika hendak meningkatkan cost harus mempertimbangkan kembali mengenai layanan yang akan didapatkan customer.

3. Customer Relationship atau hubungan pelanggan yang dimiliki PT Iron Bird ada 2, yaitu:

- Bantuan Operasional

Hubungan ini didasarkan pada interaksi antar manusia. Customer dapat berkomunikasi dengan pihak PT Iron Bird untuk mendapatkan bantuan selama melakukan proses pengiriman barang. Komunikasi ini dapat dilakukan di titik penjualan melalui call center, e-mail, atau saluran lainnya. Hubungan personal ini seperti yang diberikan PT Iron Bird kepada salah satu jenis customer yaitu customer on call basis.

- Bantuan Operasional yang Khusus

Dalam hubungan jenis ini, PT Iron Bird menugaskan petugas pelayanan pelanggan seperti bagian marketing dan customer service yang khusus diperuntukkan bagi customer. Jenis hubungan ini paling dalam dan paling intim yang biasanya dikembangkan dalam jangka panjang. Hubungan jenis ini diterapkan PT Iron Bird dengan customer khusus yaitu contract dedicate dan monthly contract.

4. Channels atau saluran yang dimiliki PT Iron Bird, yaitu:

- Konsolidasi

Sebagai perusahaan penyedia jasa transportasi, PT Iron Bird melakukan koordinasi waktu pengambilan dan pengantaran barang untuk beberapa pengirim dengan cara konsolidasi agar dapat mencapai operasional yang efisien. Konsolidasi ini dilakukan PT Iron Bird ada yang dari manufaktur ke distribution center dan dari distribution center ke beberapa retail.

5. Customer Segments atau segmen pelanggan yang dimiliki oleh PT Iron Bird ada 4, yaitu:

- Fast Moving Customer Goods (FMCG) yaitu barang-barang non durable yang diperlukan untuk penggunaan sehari-hari. Barang Fast Moving Customer Goods (FMCG) memiliki volume penjualan yang tinggi sehingga barang cepat habis. Barang Fast Moving Customer Goods (FMCG) dikelompokkan menjadi 3 kategori yaitu:
a. Perawatan pribadi seperti pasta gigi, shampo, kosmetik dan parfum.
b. Perlengkapan rumah tangga seperti detergen dan pembasmi serangga.
c. Makanan dan minuman seperti teh, kopi dan biskuit.

- Retail yaitu perusahaan yang mendistribusikan barang-barang yang dibutuhkan customer ke beberapa store.

- Pharmacy yaitu perusahaan yang bergerak dalam bidang kesehatan untuk melakukan kegiatan pembuatan obat.

- Raw Material yaitu perusahaan yang memproduksi barang setengah jadi yang kemudian dikirim ke pabrik yang akan digunakan sebagai bahan inti untuk pembuatan produk jadi.

6. Cost Structure atau Struktur Biaya yang Dimiliki oleh PT Iron Bird ada 2, yaitu:

- Fix Cost

Biaya yang dalam periode waktu tertentu jumlahnya tetap, tidak bergantung pada jumlah pengiriman yang dilakukan. Contoh fix cost PT Iron Bird seperti unit, aset, gedung dan pajak.

- Variable Cost

Biaya yang jumlahnya berubah-ubah sesuai dengan jumlah pengiriman yang dilakukan. Dalam hal ini semakin banyak jumlah pengiriman yang dilakukan, semakin besar pula jumlah biaya variabel. Contoh variable cost PT Iron Bird seperti bahan bakar minyak, parkir, tol dan komisi. 
7. Revenue Streams atau Arus Pendapatan yang dimiliki oleh PT Iron Bird, yaitu:

- Biaya Penggunaan

Arus pendapatan dihasilkan dari penggunaan layanan tertentu. Semakin sering layanan PT

Iron Bird digunakan, semakin banyak customer yang memakai dan membayar PT Iron Bird.

Analisis dan pembahasan dihubungkan antara model canvas dan proses bisnis halal logistik PT Iron Bird. Adapaun analisis dan pembahasan akan dijelaskan sebagai berikut:

1. Proses bisnis input order merupakan kegiatan yang termasuk ke dalam customer segments, karena dari proses input order PT Iron Bird akan melihat tipe industri calon customer yang sesuai dengan customer segments PT Iron Bird. Customer segments terdiri dari 4 tipe industri yaitu industri Fast Moving Consumer Goods (FMCG), retail, pharmacy dan raw material. Setiap customer di PT Iron Bird akan diberikan 3 pilihan jenis pelayanan yang diinginkan oleh customer. Layanan tersebut seperti monthly contract, contract dedicate dan on call basis. Ketiga layanan yang dimiliki oleh PT Iron Bird tersebut memiliki keterkaitan dengan customer relationship yang terbagi menjadi dua bagian yaitu:

- Bantuan operasional, yaitu bantuan yang diberikan PT Iron Bird kepada customer on call basis. Bantuan ini dilakukan melalui email atau call center yang akan didapatkan oleh customer PT Iron Bird selama melakukan proses pengiriman barang.

- Bantuan operasional yang khusus, yaitu bantuan yang diberikan oleh PT Iron Bird dengan menugaskan petugas pelayanan pelanggan yang khusus seperti bagian marketing untuk customer. Hal ini dilakukan untuk mengembangkan hubungan dalam jangka panjang. Jenis hubungan ini diperuntukkan bagi customer monthly contract dan contract dedicate. Ketiga jenis layanan seperti monthly contract, contract dedicate dan on call basis tersebut menggambarkan bagaimana PT Iron Bird berkomunikasi dan memberikan pelayanan kepada customer atau yang biasa disebut channel. Channel yang digunakan oleh PT Iron Bird adalah channel distribusi dengan cara konsolidasi. Proses konsolidasi perlu dilakukan oleh PT Iron Bird karena dapat membantu proses pengiriman barang menjadi lebih cepat, misalnya dari berbagai manufaktur ke satu distribution center dan dari satu distribution center ke beberapa retail.

2. Proses Bisnis dokumen terbagi ke dalam dua aktivitas bisnis yaitu:

- Dokumen jaminan halal.

Dokumen ini termasuk ke dalam key activities dan key resources yang harus dimiliki oleh PT Iron Bird, karena dokumen ini akan diperlukan selama proses distribusi berlangsung. Dokumen halal tersebut terpisah dari dokumen umum lain yang dibutuhkan dalam distribusi seperti delivery order dan shipping instruction. Isi dari dokumen halal terdiri dari cleaning unit dan segregasi yang dapat dipastikan lagi melalui checklist dokumen. Apabila dokumen halal telah diterapkan dalam key activities dan key resources, maka PT Iron Bird dapat memiliki value propositions seperti pengiriman yang menjamin produk halal terutama untuk Less than Truck Load (LTL) dan menciptakan proses yang transparancy serta menimbulkan kepercayaan dari customer kepada PT Iron Bird.

- Memiliki label halal.

Untuk mempermudah dalam pengiriman barang, selain memiliki dokumen jaminan halal maka PT Iron Bird harus memiliki label halal sendiri. Label halal ini berguna pada saat pengiriman Less than Truck Load (LTL) agar dapat membedakan mana barang yang halal dan tidak. Kepemilikan label halal ini berkaitan dengan key activities dan key resources yang perlu dilakukan oleh PT Iron Bird. Apabila PT Iron Bird memiliki label halal sendiri, maka akan menciptakan value propositions yang memperkuat pengiriman yang menjamin produk halal dengan memiliki label sendiri. Dengan demikian customer PT Iron Bird akan merasa memperoleh transparancy dan trust.

3. Proses Bisnis operasional terbagi ke dalam 6 aktivitas bisnis, yaitu:

- Menyiapkan driver dan unit. 
Hal ini dilakukan sebelum menjalankan proses distribusi/pengiriman. Disamping itu juga harus dilakukan cleaning unit pada saat sebelum dan setelah pemakaian. Cleaning unit ini termasuk ke dalam key activities yang harus dimiliki oleh PT Iron Bird. Selain itu, juga ada key resources yang harus dimiliki oleh PT Iron Bird yaitu adanya tim khusus untuk menangani jika ada barang yang terkontaminasi selama proses distribusi dan menyiapkan segregasi di kendaraan untuk pengiriman Less than Truck Load (LTL). Apabila PT Iron Bird tidak memiliki tim khusus, maka PT Iron Bird harus menyediakan driver yang sudah dibekali dengan pengetahuan khusus melalui pemberian pelatihan kepada driver bagaimana cara menangani barang yang terkontaminasi dan tindakan seperti apa yang harus segera dilakukan. Pada barang yang terkena kontaminasi dapat diberikan keterangan di dokumen halal. Hal ini dilakukan agar dapat membantu pada saat proses receiving, sehingga dapat dilakukan cross check untuk mengetahui mana barang yang belum dan sudah terkontaminasi. Jika key activities dan key resources tersebut sudah diterapkan oleh PT Iron Bird, maka dari value propositions akan memberikan distribusi yang on time delivery dan customer menjadi transparancy dan trust.

- Kelengkapan safety.

Dapat dilihat pada tersedianya alat safety kendaraan yang terdapat pada key resources. Apabila safety dari key resources sudah dimiliki oleh PT Iron Bird maka akan diperoleh value propositions dari segi safety dan transparancy dan trust.

- Packaging.

Dalam key activities dan key resources perlu dilakukan penyediaan packaging. Hal ini dilakukan untuk memisahkan barang yang belum terkontaminasi dengan barang lainnya apabila selama proses distribusi terjadi kontaminasi. Jika terjadi kontaminasi, maka dapat dilakukan packaging ulang untuk barang yang akan menimbulkan kontaminasi terhadap barang lainnya. Jika proses packaging ulang sudah diterapkan oleh PT Iron Bird, maka hal ini dapat menjadi value propositions bagi PT Iron Bird yang tentu saja menciptakan pengiriman atau distribusi yang menjamin produk halal dan transparancy serta trust dari customer.

- Segregasi untuk Less than Truck Load (LTL).

Dalam pengiriman Less than Truck Load (LTL) perlu dilakukan segregasi untuk menghindari barang-barang halal dari kontaminasi dengan barang non-halal. Less than Truck Load (LTL) ini merupakan pengiriman dengan muatan dalam satu unit yang berisi beberapa barang milik beberapa pengirim yang digabungkan dalam satu unit. Layanan Less than Truck Load (LTL) ini tidak hanya bisa dilakukan untuk pengiriman biasa, tetapi bisa juga dilakukan oleh pengiriman halal logistik dengan memberikan segregasi. Melalui layanan pengiriman Less than Truck Load (LTL) ini dapat memberikan kelebihan yaitu harga bisa lebih murah, tetapi barang tetap mendapatkan jaminan halal. Oleh karena itu, dalam key activities dan key resources PT Iron Bird harus memiliki segregasi. Adanya segregasi dapat menciptakan pengiriman atau distribusi yang menjamin produk halal dan transparancy serta trust dari customer kepada PT Iron Bird.

- Membuat dokumen halal. Dokumen halal diperlukan oleh PT Iron Bird dalam setiap melaksanakan kegiatan distribusi. Dokumen halal dapat dipergunakan sebagai checklist bahwa proses yang terkait dengan halal logistik telah terlaksana dengan baik. Oleh karena itu, pada key resources dan key activities dokumen halal tersebut harus dimiliki oleh PT Iron Bird. Adanya dokumen halal dapat memberikan pengiriman atau distribusi yang menjamin produk halal dan menciptakan transparancy serta trust dari customer.

- Menempelkan label pengiriman halal.

Dalam key activities dan key resources PT Iron Bird harus memiliki label halal. Penempelan labeling halal ini dapat diberikan pada tiap pallet atau tiap kardus barang sebagai penanda antara barang yang dikirimkan dengan pengiriman halal logistik dan pengiriman biasa.

4. Proses Bisnis monitoring terbagi ke dalam 3 aktivitas bisnis, yaitu:

- Memantau dan melaporkan posisi unit. 
Dalam hal ini terkait dengan key activities yaitu distribusi/pengiriman barang. Dari key activities tersebut PT Iron Bird memiliki value propositions yaitu pengiriman yang menjamin produk halal, kelengkapan alat safety dalam pengiriman, dan dapat memberikan pengiriman yang on time delivery

bagi customer serta dapat memberikan transparancy dan trust dari customer kepada PT Iron Bird.

- Evaluasi ke customer

Proses evaluasi penting dilakukan oleh PT Iron Bird. Proses evaluasi dapat menunjukkan rasa kepedulian hubungan bisnis terhadap customer dan dapat menciptakan kerjasama dalam jangka panjang. Evaluasi dilakukan untuk mengetahui tingkat kepuasan customer melalui kinerja yang telah diberikan oleh PT Iron Bird. Hasil dari evaluasi dapat berupa laporan yang bisa dijadikan bahan koreksi bagi PT Iron Bird. Apabila tingkat kepuasan customer rendah, maka itu menjadi sebuah tantangan bagi PT Iron Bird untuk meningkatkan lagi kinerjanya dan apabila tingkat kepuasan customer tinggi, maka itu menjadi sebuah nilai tambahan bagi PT Iron Bird yang harus dipertahankan. Adanya proses evaluasi ini bisa menjadi value propositions bagi PT Iron Bird terhadap customer.

- Key Performance Indicators (KPI) Hasil yang sudah didapatkan dari evaluasi dapat diukur oleh PT Iron Bird melalui Key Performance Indicators (KPI) yang sudah ditetapkan. Hasil dari evaluasi apabila di minta oleh customer dapat diberikan oleh PT Iron Bird agar menjadi value added, namun apabila tidak diminta hasil evaluasi tersebut tetap harus menjadi kewajiban bagi PT Iron Bird untuk tetap melakukan evaluasi.

5. Proses bisnis delivery terbagi ke dalam 1 aktivitas bisnis, yaitu:

- Pemeriksaan kesehatan driver

Proses bisnis delivery ini merupakan proses pengiriman barang yang dilakukan oleh PT Iron Bird setiap harinya. Selain melakukan pengiriman barang, sebaiknya PT Iron Bird juga melakukan pemeriksaan kesehatan untuk driver dan memeriksa kelengkapan kendaraan. Adanya pemeriksaan kesehatan dan kelengkapan kendaraan ini terkait dengan key resources yang harus dimiliki oleh PT Iron Bird, sehingga dapat memberikan value propositions bagi customer berupa safety dan transparancy serta trust.

Untuk cost structure, dapat dibagi menjadi 2 yaitu:

- Fix cost sebagai biaya tetap yang akan dikeluarkan PT Iron Bird dari kegiatan key resources. Fix cost di PT Iron Bird berupa asset, unit, gedung, dan pembayaran pajak.

- Variabel cost sebagai biaya tambahan diluar dari fix cost. Biaya tambahan ini akan dikeluarkan PT Iron Bird tergantung dari key activities, key resources dan jenis pelayanan. Hal ini dikarenakan, tiap customer melakukan order dengan layanan yang berbeda-beda, maka variabel cost yang dikeluarkan juga berbeda tergantung kesepakatan PT Iron Bird dan customer. Misalkan pada monthly contract variable cost dapat dibayarkan per dua minggu sekali, pada on call basis variabel cost sudah include untuk satu kali perjalanan, dan pada contract dedicate disesuaikan dengan kontrak yang disepakati dengan kedua belah pihak. Variabel cost dan fix cost dapat menjadi value propositions bagi PT Iron Bird berupa cost yang sesuai dengan pelayanan yang diberikan.

Untuk perhitungan revenue streams dapat dijelaskan sebagai berikut:

- Bruto adalah pendapatan keseluruhan dari suatu bisnis yang dijalankan oleh PT Iron Bird yang berasal dari semua sumber termasuk variabel cost dan fix cost. Bruto di PT Iron Bird dihasilkan dari fix cost ditambah variabel cost.

- Margin adalah keuntungan yang didapatkan oleh PT Iron Bird. Margin di PT Iron Bird dihasilkan dari nilai atau harga yang berbeda-beda karena PT Iron Bird memberikan harga yang berbeda untuk setiap customer sesuai dengan kerjasama dan negosiasi yang disepakati. 
- $\quad$ Revenue di PT Iron Bird didapatkan oleh PT Iron Bird dari penghasilan bruto dikali dengan hasil margin.

\section{KESIMPULAN}

Berdasarkan hasil pengumpulan dan pengolahan data, maka dapat diambil kesimpulan sebagai berikut:

1. Melalui proses bisnis dapat diketahui bagaimana alur bisnis, aktivitas bisnis yang dilakukan mulai dari proses distribusi, cleaning unit, segregasi dan dokumen pembersihan, labeling, dan pengemasan bagi barang yang terkontaminasi serta siapa saja pelaku bisnis yang terlibat di PT Iron Bird maupun customer PT Iron Bird.

2. Model bisnis halal logistik yang dapat diterapkan untuk PT Iron Bird adalah Business Model Canvas (BMC) yang dibagi menjadi 4 kategori, yaitu:

\section{- Customer}

Sesuai dengan customer segments, maka PT Iron Bird dapat memperluas pencarian customer yang memiliki potensi dalam halal logistik seperti industri fast moving consumer goods, retail, raw material dan pharmacy.

- Penawaran

Sesuai dengan value propositions, maka PT Iron Bird dapat memberikan penawaran kepada customer mengenai pengiriman yang menjamin produk halal, pendistribusian untuk pengembalian barang atau return, segregasi untuk Less than Truck Load (LTL), packaging ulang untuk barang yang terkontaminasi, label dan dokumen halal, pembersihan unit yang sesuai standar, kelengkapan safety, transparancy dan trust, on time delivery, dan cost yang sesuai dengan pelayanan yang diberikan.

- Resource Sesuai dengan key resources, maka PT Iron Bird dapat mengelola sumber daya utama melalui tim khusus untuk menangani barang yang terkontaminasi, ketersediaan kendaraan, layanan yang diberikan, pengemasan untuk barang yang terkontaminasi dan label serta dokumen halal.

- Financial

Sesuai dengan revenue streams, maka PT Iron Bird dapat meningkatkan financial melalui layanan yang diberikan. Customer akan bersedia membayar lebih jika memang customer merasa puas dan sesuai dengan standar halal yang ditawarkan oleh PT Iron Bird.

3. Halal logistik yang diterapkan di PT Iron Bird, telah memperoleh Key Performance Indicators (KPI) yang seuai dengan standar halal logistik. Key Performance Indicators (KPI) tersebut terdiri dari:

- Quality

- Time

- Cost

- Risk

- Relationship

\section{REFERENSI}

1) Tieman, M. and Ghazali, MC.(2013).Principles in Halal Purchasing. Journal of Islamic Marketing, Vol. 4(3): 281-293.

2) Jaafar,S.N, Lalp ,P.E ,Mohamed,M.(2012). Consumers Perceptition Attitudes and Purchase Intention towards Private Label Food Products in Malaysia.Asian Journal of Business and Management Sciences, Vol 2. No.8 [73-90]

3) Kamaruddin,Rohana, Hadijah Ibrahim,Alwi Shabudin.(2012). Willingness to Pay For Halal Logistics: The life style Choice.Procedia-Social and behaviourial Science 50(2012)722-729.

4) Bruil,RR. (2010). Halal logistics and the impact of consumer perceptions. Business Administration ,Master Track International Management School of Management and Governance.Master Thesis. 
5) Bowersox, D.J, David, C.J, Cooper, M.B.2002.Supply Chain Logistic York: The McGraw-Hill Companies.

6 ) Herawati,Novita , Triana Lindriati, Ida Bagus Suryaningrat.2019. Penerapan Bisnis Model Kanvas Dalam Penentuan Rencana Manajemen Usaha Kedelai Edamame Goreng.Jurnal Agroteknologi, Vol 13 no (1)[42-51].

7) Osterwalder, A. \& Pigneur, Y. 2015. Business Model Generation. 2015. Jakarta: PT Elex Media Komputindo. 